\title{
ИНСТРУМЕНТЫ КОРПОРАТИВНОГО УПРАВЛЕНИЯ, ПОЗВОЛЯЮЩИЕ ОСУЩЕСТВЛЯТЬ КОНТРОЛЬ УЧАСТИЯ КОРПОРАЦИИ В ЮРИДИЧЕСКИХ ЛИЦАХ
}

\section{CORPORATE GOVERNANCE TOOLS THAT ALLOW YOU TO CONTROL THE CORPORATION'S PARTICIPATION IN LEGAL ENTITIES}

\section{S. Sokolova}

Summary. The article is based on the analysis of corporate law regulating supervision on holding of subsidiary and applicable judiciary practice. In addition, the author tries to ground that the mandatory or discretionary nature of the corporate laws should not be opted, focusing only on the formal attributes of dispositivity fixed in the law.

Keywords: corporation, business company, corporate governance, authority.

\author{
Соколова Светлана Михайловна \\ Аспирант, МГУ им М.В. Ломоносова, г. Москва \\ smsokolova94@gmail.com
}

Аннотация. Статья посвящена анализу норм корпоративного законодательства, регулирующих осуществление контроля над участием корпорации в юридических лицах и судебной практике их применения. Помимо этого, автором осуществлена попытка доказать то, что императивный или диспозитивный характер рассматриваемых норм корпоративного законодательства не стоит оценивать, ориентируясь лишь на формальные атрибуты, содержащиеся в норме.

Ключевые слова: корпорация, хозяйственное общество, корпоративное управление, компетенция.
B ажной частью корпоративного управления являются вопросы, связанные с закреплением структуры органов управления юридического лица, распределением и разграничением их компетенции.

Указанная выше проблематика регулируется Гражданским кодексом РФ от 30 ноября 1994 года N51-Ф3 (далее - ГК РФ), федеральным законом от 08.02.1998 N14-Ф3 «О6 обществах с ограниченной ответственностью» (далее - Ф3 об ООО), федеральным законом от 26.12.1995 N208-Ф3 «Об акционерных обществах» (далее - Ф3 об АО), иными правовыми актами и уставом хозяйственного общества.

Оставляя за пределами настоящей статьи обсуждение целей и причин регулирования корпоративных отношений императивными нормами, можно констатировать, что с помощью диспозитивного и императивного регулирования законодатель в том числе формирует различные виды компетенций органов юридического лица. В частности, по основанию возможности передачи части полномочий иным органам юридического лица можно выделить следующие виды компетенций общего собрания участников (акционеров) хозяйственного общества: 1) исключительную компетенцию, т.е. тот круг вопросов, принятие решений по которым не может быть передано от общего собрания участников (акционеров) другим органам корпорации, например, вопросы, связанные с изменением устава, ликвидацией общества и проч. 2) альтернативную компетенцию, т.е. круг вопросов, вынесение решения по которым может быть с помощью устава передано другим органам юридического лица, например, в уставе непубличного общества можно предусмотреть передачу в компетенцию совета директоров вопросов, связанных с образованием единоличного исполнительного органа, утверждения аудитора и проч.

При установлении круга вопросов, отнесенных к исключительной компетенции общего собрания участников (акционеров), законодатель, с одной стороны, пытается сбалансировать проблему противоречия интересов участников хозяйственного общества и менеджмента, а, с другой стороны, предлагает механизм защиты прав и интересов миноритариев.

В силу ряда причин российский бизнес в значительном числе случаев организован по принципу вертикальных холдингов, поэтому проблемы, связанные с корпоративным управлением в части контроля участия корпорации в других юридических лицах, часто встречаются на практике.

Под контролем участия корпорации в других юридических лицах в рамках настоящей статьи понимается принятие компетентным органом решений о созда- 
нии корпорацией других юридических лиц, об участии (приобретении доли или акций) и о прекращении участия общества в других организациях. Вопросы, связанные с контролем участия корпорации в других юридических лицах, могут затрагивать следующие отношения: 1) создание обществом дочернего общества, 2) принятие обществом решения о ликвидации или реорганизации дочернего общества, 3) выход общества из состава участников дочернего общества, 4) заключение обществом договора купли-продажи доли (акций) в качестве покупателя или продавца, 5) приобретение обществом доли посредством увеличения уставного капитала за счет дополнительных вкладов третьих лиц; 6) отчуждение доли (акций) другого общества вследствие реализации залога, заключения мирового соглашения и проч.

Далее попробуем выяснить, императивно или диспозитивно регулируется осуществление контроля участия корпорации в других юридических лицах. Для выявления природы данных положений сначала обратимся к буквальному толкованию регулирующих соответствующие отношения норм.

Согласно абз. 7 п. 2 ст. 65.3. ГК РФ, если иное не установлено ГК РФ или другим законом, принятие решений об участии корпорации в других юридических лицах отнесено к исключительной компетенции общего собрания участников (акционеров), но при этом сделана оговорка про то, что уставом общества в соответствии со специальными законами принятие таких решений может быть отнесено к компетенции иных коллегиальных органов управления общества. При формулировании рассматриваемой нормы законодатель использует оговорки нескольких уровней: 1) если иное не установлено ГК РФ, 2) если иное не установлено другим законом, 3) когда иное установлено уставом общества в соответствии со специальным законом.

Помимо оговорок в рассматриваемой статье ГК РФ законодатель использует такой формальный атрибут императивности, как термин «исключительная компетенция».

Обращаясь к первой оговорке, необходимо иметь в виду пп. 1. п. 3. ст. 66.3. ГК РФ, зафиксировавший возможность включения в принятый единогласным решением общего собрания участников (акционеров) устав непубличного общества положений о передаче на рассмотрение коллегиального органа управления общества или коллегиального исполнительного органа общества вопросов, отнесенных законом к компетенции общего собрания участников хозяйственного общества. Принятие решений об участии корпорации в других юридических лицах не включено в перечень вопросов, которые нельзя передать в соответствии с указанной статьей. При этом необходимо помнить про п. 2. ст. 67.1. ГК РФ, закрепляющий исключительную компетенцию общего собрания участников хозяйственного общества наряду с п. 2. ст. 65.3. ГК РФ, закрепляющим исключительную компетенцию высшего органа корпорации. То есть рассматриваемая оговорка не позволяет сделать вывод об императивности или диспозитивности правила, регулирующего контроль участия корпорации в других юридических лицах.

Обращаясь ко второй и третьей оговорках, в ст. 33. Ф3 об ООО вопросы, связанные с участием корпорации в других юридических лицах, не отнесены к компетенции общего собрания, только в пп. 4. п. 2.1. ст. 32. указанного закона предусмотрено, что совет директоров (в случае его образования) выносит решения по вопросам, связанным с принятием решения об участии общества в ассоциациях и других объединениях коммерческих организаций. При этом согласно пп. 4. п. 2.ст. 40. Ф3 об ООО компетенция единоличного исполнительного органа определена как остаточная, то есть все, что не относится к компетенции общего собрания участников общества, совета директоров (наблюдательного совета) общества и коллегиального исполнительного органа общества в соответствии с Ф3 об ООО и уставом, является компетенцией единоличного исполнительного органа.

На основании пп. 17.1. п. 1 ст. 65. Ф3 об АО можно констатировать, что принятие решений об участии акционерного общества в других организациях отнесено к компетенции совета директоров при условии, что уставом общества принятие решения по указанному вопросу может быть отнесено к компетенции исполнительных органов общества. Общее собрание акционеров в соответствии с пп. 18. п. 1. ст. 48 Ф3 об АО принимает решение только по вопросу участия в финансово-промышленных группах, ассоциациях и иных объединениях коммерческих организаций. В соответствии с п. 3. и п. 4. ст. 48. Ф3 об АО полномочия на принятие решений об участии или прекращении участия в других организациях могут быть переданы уставом непубличного общества, принятым единогласно, общему собранию акционеров, а в публичном обществе подобная альтернатива не предусмотрена. Компетенция единоличного исполнительного органа в акционерном обществе также определена как остаточная (п. 2. ст. 69.Ф3 об АО).

В п. 307 имеющего для акционерных обществ, чьи ценные бумаги которых допущены к организованным торгам, рекомендательный характер кодекса корпоративного управления в качестве лучшей практики указано распространение с помощью устава механизма одобрения крупных сделок на сделки по созданию под- 
контрольных юридических лиц, а также сделки по продаже акций (долей) подконтрольных обществу юридических лиц, имеющих для него существенное значение, в результате совершения которых общество утрачивает контроль над такими юридическими лицами.

Резюмируя анализ специального законодательного регулирования контроля участия корпорации в других юридических лицах, можно прийти к выводу, что в случае отсутствия в уставе общества положений по этому вопросу, он в обществе с ограниченной ответственностью или непубличном акционерном обществе решается советом директоров (в случае его создания) или единоличным исполнительным органом, а в публичном акционерном обществе - советом директоров (наблюдательным советом).

По вопросу соотношения процитированных выше норм ГК РФ и положений специальных законов необходимо заметить, что согласно п. 4 ст. 3 Федерального закона от 05.05.2014 N99-Ф3 «О внесении изменений в главу 4 части первой Гражданского кодекса Российской Федерации и о признании утратившими силу отдельных положений законодательных актов Российской Федерации» специальные законы применяются, если они не противоречат положениям ГК РФ в редакции указанного закона.

Завершая анализ всех оговорок, можно прийти к выводу, что формальное толкование не позволяет однозначно говорить о диспозитивности или императивности нормы абз. 7 п. 2. ст. 65.3. ГК РФ.

Возвращаясь к инструментам корпоративного управления, позволяющим осуществлять контроль участия корпорации в юридических лицах необходимо заметить, что вопросы, связанные с участием общества в других организациях, могут быть связаны с распоряжением значительной частью активов общества, но при этом регулирование, установленное в отношении крупных сделок, к ним не будет не применимо в силу ряда причин.

Во-первых, согласно п. 21 приказа Минфина России от 10.12.2002 N126н «Об утверждении Положения по бухгалтерскому учету «Учет финансовых вложений» ПБУ 19/02» финансовые вложения, по которым текущая рыночная стоимость не определяется (а к этой категории относятся доля в уставном капитале ООО или акции, которые не торгуются на бирже), подлежат отражению в бухгалтерском балансе по первоначальной стоимости (то есть в учете отражена сумма фактических затрат общества на их приобретение, за исключением налога на добавленную стоимость и иных возмещаемых налогов). Данное регулирование приводит к тому, учет стоимости доли (акций) в бухгалтерском учете будет отличаться от их реальной стоимости и в связи с этим, значительный и важный актив общества, потенциально являющийся основой деятельности общества, может быть выведен, например, путем заключения договора купли продажи доли в уставном капитале общества по их номинальной стоимости и без согласования с участниками (акционерами), так как эта сделка не является крупной. Во-вторых, оспаривание в случае прекращения участия вследствие реализации права на выход общества из состава участников другого общества или принятия решения о ликвидации общества и проч. со ссылками на нормы, регулирующие крупные сделки или сделки с заинтересованностью, вызывает ряд практических и теоретических вопросов и не всегда возможно.

Обратимся к анализу судебной практики по вопросу контроля участия корпорации в юридических лицах. Подтверждением уже ранее отмеченной в настоящей статье противоречивости законодательного регулирования того, какой орган юридического лица может принимать решения об участии общества в других организациях, является отсутствие единообразия судебной практики. Так, часть судов считает, если иное не отражено в уставе, что так как в п. 2. ст. 33. Ф3 об ООО принятие решений об участии общества в других юридических лицах к компетенции общего собрания не отнесено, то контроль участия общества в других юридических лицах не относится к исключительной компетенции общего собрания. Часть судов придерживается позиции, что контроль участия общества в других юридических лицах относится к исключительной компетенции общего собрания на основании п. 2. ст. 65.3. ГК РФ вне зависимости от указания на это уставом общества.

В связи с тем, что не решен вопрос о том, являются ли сделки, связанные с одобрением участия или прекращения участия корпорации в других юридических лицах, одобряемыми в соответствии с законом или в соответствии с уставом, то неясен порядок и основания их обжалования (оспаривание в силу положений ст. 173.1. ГК РФ с ссылкой на п. 2. ст. 65.3. ГК РФ или 174. ГК РФ ссылкой на п. 2 ст. 69 ФЗ об АО и п. 3.1 ст. 40 ФЗ об ООО). Указанная правовая неопределенность значительно затрудняет защиту интересов участников (акционеров) на практике.

Если в уставе общества указано на то, что решение об участии общества в других организациях относится к исключительной компетенции общего собрания участников общества или совета директоров, то заявление генерального директора общества о выходе из состава участников должно основываться на решении общего собрания участников или совета директоров. 
Схожую логику можно применить к заявлению третьего лица о принятии его в общество и внесении вклада. В постановлении десятого арбитражного апелляционного суда от 21 июня 2018 года по делу А41-98135/17 сделан вывод о том, выход из состава участников является сделкой, совершенной лицом, чьи полномочия ограничены уставом общества, отсылки на ст. 65.3. ГК РФ в постановлении нет.

Если в уставе общества указано на то, что решение об участии общества в других организациях относится к исключительной компетенции общего собрания участников общества, то голосование директора контролирующей компании по вопросу ликвидации дочерней компании на общем собрании участников последней должно быть основано на решении общего собрания участников контролирующей компании.

Дела, связанные с созданием подконтрольных обществ, ликвидацией подконтрольных обществ также еще осложнены тем, что связаны с вопросом признания за бенефициаром, не имеющим непосредственного участия в обществе, права на обжалование решений, принятых контролируемым обществом. Констатировать это можно по причине того, что в законодательстве нет однозначного ответа на вопрос о том, может ли бенефициар обжаловать решения общества или предъявлять требования в интересах общества, формально не являясь участником последнего. Так, в деле ООО «Студенческий стиль» ООО «Балтик Трэвэл Бас Плюс», являясь владельцем 55\% доли в уставном капитале ООО «Маркор-Нева-Отель», обратилось в суд с требованиями о признании недействительным договора купли-продажи доли в уставном капитале ООО «Студенческий стиль», заключенного между ООО «Маркор-Нева-Отель» (продавец) и третьим лицом, и признании права ООО «Маркор-Нева-Отель» на указанную долю. Суд вынес решение об отказе в исковых требованиях по причине того, что ООО «Балтик Трэвэл Бас Плюс» не обладает правом предъявления требования о признании права на долю в интересах ООО «Маркор-Нева-Отель». А в деле ООО «Деловой Альянс» участник ООО «СВК» обратился в суд с требованием о признании решения о ликвидации ООО «Деловой Альянс», чьим единственным участников являлось ООО «СВК», недействительным. Суд первой инстанции вынес решение о том, что истец, не являясь участником ООО «Деловой Альянс», не имеет права обжалования принятых ООО «Деловой Альянс» решений. Суд апелляционной инстанции, наоборот, признал заинтересованность участника ООО «СВК» в обжаловании решения о ликвидации ООО «Деловой Альянс».

Отчуждение части доли (акций) одного общества в уставном капитале другого общества не требует одобрения в соответствии с абз. 7 п. 2 ст. 65.3. ГК РФ, так не влечет за собой прекращения участия общества в другой организации. Не имеет значения отчуждена ли незначительная доля (часть акций) или доля (акции), позволяющая контролировать деятельность общества. Нельзя не отметить, что формальное чтение рассматриваемых норм может повлечь существенное ущемление интересов участников общества со стороны менеджмента или притеснение мажоритарием интересов миноритария.

Подводя итоги, можно констатировать, что несмотря на то, что вопросы, связанные с приобретение и отчуждением доли (акций) в других организациях, могут существенно влиять на деятельность общества, законодательное регулирование приятия решений о создании подконтрольных компаний, участии и прекращении участия хозяйственного общества в других организациях сформулировано непоследовательно и неполно. Опираясь на формальные атрибуты норм, нельзя прийти к выводу об императивности или диспозитивности регулирования данного круга вопросов. Соотнесение ГК РФ и специального законодательства, также не представляется однозначным.

По нашему мнению, в текущей ситуации контроль над участием общества в других корпорациях в непубличных обществах должен быть отнесен к исключительной компетенции общего собрания участников (акционеров) на основе диспозитивной нормы, применяемой участниками по умолчанию, то есть за исключением случаев, когда они специально не предусмотрели в уставе иное регулирование. В публичных обществах на основе императивной нормы - к компетенции совета директоров (наблюдательного совета). Порядок одобрения может быть схож с порядком, применимым к крупным сделкам, так как в рассматриваемом случае речь также идет об активах, которые могут оказать существенное влияние на деятельность общества. При этом следует предусмотреть возможность дифференцированного регулирования, предоставив одобрение участия или прекращение участия общества в других организациях общему собранию участников (акционеров) и совету директоров (наблюдательному совету). Представляется правильным, что при прекращении и начале участия в уставном капитале другого лица или изменении доли участия, повлекшим существенное изменение в деятельности общества, решение вопроса об одобрении должно находиться в компетенции общего собрания участников (акционеров). Например, как это сделано в п. 16. постановления пленума Верховного суда РФ от 26 июня 2018 г. № 27 «Об оспаривании крупных сделок и сделок, в совершении которых имеется заинтересованность», в соот- 
ветствии с которым принятие решения об одобрении сделки, предметом которой является имущество, стоимость которого превышает 50\% балансовой стоимости не может быть отнесено уставом общества к компетенции иных органов общества ${ }^{1}$.
В связи с предложенным выше, на порядок обжалования сделок, связанных с участием хозяйственного общества в других организациях логично распространить порядок обжалования крупных сделок, обозначенный в ст. 173.1. ГК РФ.

\section{ЛИТЕРАТУРА}

1. Маковская А.А. Императивные и диспозитивные нормы в корпоративном законодательстве (ошибки в формулировках, проблемы толкования и правоприменения) // Вестник гражданского права. 2019. ⒌ С. 79-109.

2. Козлова Н.В., Филиппова С.Ю. Качественный критерий квалификации крупной сделки, совершаемой хозяйственным обществом // Российский юридический журнал. 2020. ⒍ С. 118-129.

3. Кузнецов А.А. Пределы автономии воли в корпоративном праве: краткий очерк. М.: Статут. 2017. 160 с.

4. Суханов Е.А. Комментарий к ст. 65.1. - 65.3. ГК РФ // Вестник гражданского права. 2014. № 3. С. 107-130.

\section{() Соколова Светлана Михайловна ( smsokolova94@gmail.com ).}

Журнал «Современная наука: актуальные проблемы теории и практики»

1 Подробнее о вопросе соотношения императивных и диспозитивных норм в регулировании института крупных сделок см. Маковская А.А. Императивные и диспозитивные нормы в корпоративном законодательстве (ошибки в формулировках, проблемы толкования и правоприменения) // СПС «КонсультантПлюс».

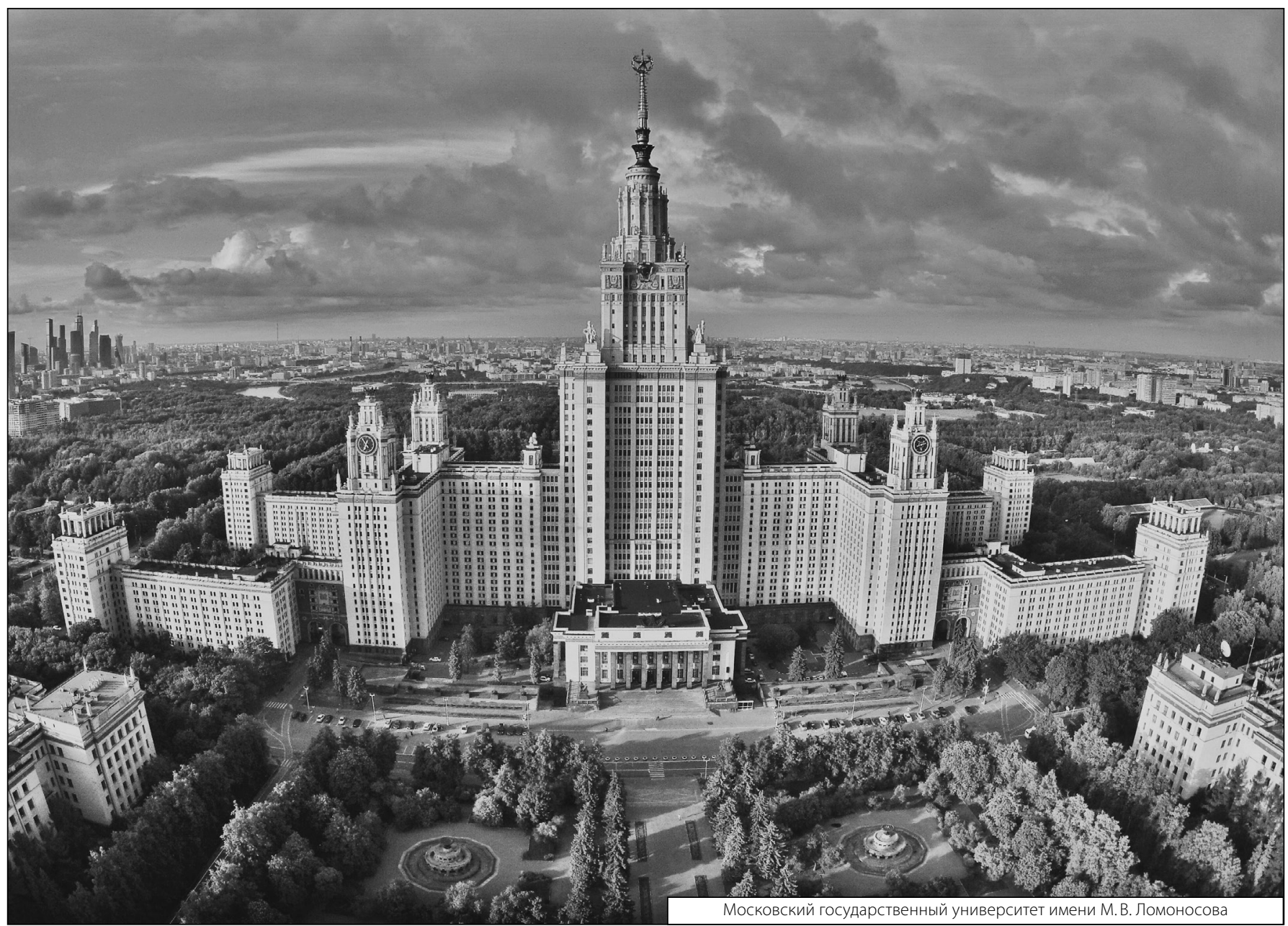

